positively impact property rights reforms. "Sociocultural, economic, political and spiritual" development should be better rather than more.

Finally, Stevenson, Burkett and San Myint discuss how what they call "integrated communications and information technology" such as digital video applications can expedite connections between local communities on a global scale and encourage decentralization. They provide the example of the Local/Global Netweaving Program in Australia, founded on the principles of connection between local and global communities, participation in both local and global activities, communication, and practical action. Importantly, the authors stress that interactive information technology must be supported by a framework of use in line with values that recognize equality of persons "irrespective of economic background, race, gender, geography, or other characteristics." The alternative, they insist, is a future in which machines shape and control societies.

This scattered and uneven collection of essays will be most useful for nonspecialist readers interested in examples of local approaches to sustainable community development. The importance of quality of life in notions of sustainability, the effectiveness of community-level governance, and Community Land Trusts as an alternative to wholly public or private home ownership are particularly memorable topics. Although it is not well suited for the classroom or as an academic resource, the casual reader by judiciously skipping about with an interest in the issues likely will become better informed and possibly inspired to investigate further.

\title{
Earth's Insights: A Multicultural Survey of Ecological Ethics from the Mediterranean Basin to the Australian Outback by J. Baird Callicott, with a Foreword by Tom Hayden (1997) Berkeley : University of California Press, 285 pp.
}

\section{Reviewed by Dipak R. Pant, Professor of Economic Anthropology and Applied Anthropology, University of Castellanza (VA), Italy}

Earth's Insights covers some challenging terrain in the field of comparative environmental ethics, a field too little explored by scholars. Callicott, professor of philosophy and religious studies at the University of North Texas, constructs for us a framework for the comparative study of ethics and environmental values, and for examining the susceptibility of both to historical change. Implicit in this tour is a notion that we might turn to non-Western sources of inspiration to chart a course for a more sustainable future.

The first question Callicott poses is: What is the equivalent of "ethics" in traditional non-Western societies? As he acknowledges, ethics do not exist in a vacuum, hermetically sealed off from larger systems of ideas (or, for that matter, from the rough-and-tumble of the real world). Ethics must be viewed, instead, like any other spheres of human thought and action (science, technology or law) in a broad frame of differences--of problems perceived and solutions attempted--by peoples of different places and times, in different 
terms and under different conceptual banners. Callicott's jump-start with a philosophical discourse on ethics is quite problematic, however, as he does not first provide us with a well-enough grounded panorama of ethics-like thought in non-Western traditions. From the outset, one is left wondering about how well his conceptualization of ethics travels across time and place.

The going does not grow easier. Dealing with the historical roots of Western environmental attitudes and values (Chapter 2), Callicott repeats an oversimplification promoted by many other Western scholars. Only Judeo-Christian and Greco-Roman heritage's are taken into consideration, while overlooking the more richly textured mosaic of local "little" traditions of Celts, Iberians, Italics, Teutonics, Nordics, Slavs, and so forth. The pre-industrial Western rural traditions were expressions of some powerful and persistent undercurrents that have survived even to contemporary times in different folk forms. Yet Callicott disregards the surviving rural folklore in Europe. The Christian traditions, particularly Roman Catholicism, have absorbed and preserved many polytheistic, polycentric and nature-worshipping elements that are yet to be seriously studied to comprehend the environmental attitude and values of Western peoples. In the Alpine region and in many parts of central and southern Europe, for example, one can still find the sacred geography (e.g., "Madonna of the Snow," "St. Michael of the Mountaintop," many saints and holy figures associated with summits, lakes, rivers, boulders and so on). The European rural-popular sacred geography contains a highly articulated land ethic and a rough cosmography--most probably of pre-Christian origins, absorbed and modified by the medieval Christianity. It is a pity that the author fails to notice such a widely present and interesting aspect of the European culture.

Callicott appears to confound history and tradition. History is contingency, whereas tradition is continuity. Many elements do change forms and adapt to new circumstances to survive; and that produces history. Unforeseen changes (climate change, disasters, encounters and clashes of cultures) force the traditions to take different shape and to be articulated in different ways; all that is history. Yet Callicott does not clearly indicate which traditional attitudes and values (regarding the environment) have changed under which historical circumstances. He does not explain, for example, how the Western idea of nature as God's expression (omnis natura Deo lognitur, Hugo of St. Victor, Erudito Didascalica, 6.5, p. 176, 1805) degenerates to the idea of nature as the unlimited resource to be possessed by people. Nor does he clearly explain how the Old Testament concepts of "God's creation" and "the centrality of humans" were turned to be "man-nature fellowship under the God's patronage" in the medieval mysticism (a good example would be the teachings of St. Francis of Assisi).

Similar problems can be found in the author's oversimplified characterization of Islamic environmental ethics. The author totally ignores the Sufi tradition and the underlying nondualistic (almost pantheistic) mysticism expressed in the esoteric Islam, for example, the highly influential works of Jalaluddin Rumi and Mansur al-Hajjaj. Islamic esoterism has been somewhat different from the Judaic and Christian varieties. The influence of Sufi doctrines and practices in mainstream Islamic cultures is far more incisive than that of Jewish Kabbala or Christian esoterism in their respective sociocultural mainstreams.

The author is quite right in pointing out that the place of Islam is in the "West" rather than in the "East." But again, the role of Islamic mysticism (the variety of Sufi traditions in North Africa, the Middle East, Central Asia) in bridging the gap among the pre-Islamic, 
non-Islamic, and Islamic traditions and the environmental attitudes and values generated by such intercultural dialogue are overlooked.

The author's understanding of the Dharma traditions (the so-called Hinduism, Buddhism, and Jainism, Chapter 3) is quite problematic. As with most contemporary Western observers, the author takes Vedanta of Shankara (eighth century A.D.) as the representative central idea of so called Hinduism (in reality, there is no "ism" as Hinduism), and Shunya-vada (or Madhyamika) as the governing principle of Buddhism. This may appear so to the bookish scholars who understand (or confuse) tradition to be a historical succession of schools of thought.

The reality is very different from the scholarly appearance, however. The demarcating lines among Hindu, Buddhist, Jaina and other tribal and shamanic traditions of the Indian subcontinent and the Himalayan region are terribly misleading. The doctrinal contents are always articulated through social channels such as family cults (Kula-parampara), scenic and social representations and recitals (Lila-parampara), and pilgrimage (Tirthaparampara). The Dharma texts speak often in a cryptic and codified manner whereas the articulation in social mainstream is direct and decodified. Most Western scholars, Callicott included, fail to grasp fully the complementarity and parallelism of the textual and oral traditions of India, Nepal, Tibet, and many other parts of South and Southeast Asia. Without a careful empirical study of the living forms one is bound to add more enigma and confusion to the already complex and enigmatic reality of South Asian traditions. A more serious problem with Earth's Insights and its treatment of ethical frames from the Indian subcontinent, however, is the book's inattention to the Tantric traditions, which are at the core of Indian, Tibetan, Nepalese, Sri-Lankan, and other Asian systems of relating and dealing with the mind-body complex, with nature and environment.

Callicott's understanding of human-environment relations in China is overloaded by aesthetic appraisal, and lacks critical overview. After reading the book all the way through, one gets the impression that the author views Chinese environmental thinking as the "best" one (from the viewpoint of today's environmentalist). Yet among all the Asians, the Chinese have been the most determined actors on the environment (for example, great walls, grand pavilions, artificial lakes, iron shoes to keep the women's feet little and tender, castration of young males to have regiments of eunuchs). Chinese culinary art is rich and it includes nearly every little or big beast known to the Chinese (one of the most elite delicacies used to be a live monkey's warm brain by opening the skull right at the moment of dining). Callicott does not seem to take seriously these cultural traits; there is no explanation about such sophisticated and forceful attitude to other creatures and towards the environment.

In the 1960s, the Chinese officialdom undertook a huge, self-conscious venture of mass mobilization to destroy the magico-religious traditions and sacred geography of the people (the Cultural Revolution). In recent decades, the scale of environmental destruction and landscape modification in China is without any precedence in Asian history. Callicott does not appear to question why the heirs of an ancient civilization so enthusiastically carried out a self-conscious process of eradicating the "sacred" from the landscape and social life.

A sound empirical survey of the Chinese society, institutions and history would have certainly helped Callicott to understand better that the mainstream Chinese culture is substantially this-worldly, with more focus on person-collectivity (person-to-person) relations and least concerned with the human-nature relationship. Only the Buddhist 
(imported from India) and Tao (not so dominant in Chinese civilization) traditions have shown some cosmos orientedness compared to Confucianism-dominated mainstream. Even in the Buddhist and Tao traditions the Chinese have always longed for "longevity" (through medical-alchemical pursuits) and pragmatic wisdom (in relations to the world and with the others) rather than compassion or freedom. The Confucian, the communist, and the neo-Confucian (the modern social and political thinking of Chinese-born elites of Singapore and other Southeast Asian countries) ideologies are staunch supporters of the traditional Chinese view that collectivity is above the individual person and that the state is above the society (contrary to the other Asians including the Japanese and the Indians who put society above the state). What is the ramification of such ideas and practices in the attitude towards nature and fellow creatures ? How is it that the Chinese come to be more rampant in their materialistic pursuits and consumptive ways of life among all other Asians today? Callicott fails to deal properly with such fundamental questions.

Similar questions about Japanese environmental ethics remain unanswered: how the forceful and highly sophisticated subduing of nature (e.g., bonsai, the art of dwarfing the tree species, and ikebana, the art of manipulating plants and flowers for decoration) came to be so widely popular in a tradition where the ecological insights are supposedly so fine and kind for the author. Callicott's last chapter on activism does not mention a single environmental opinion and action movement of China or Japan, nor does he explain why. The understanding of the Eastern environmental ethics displayed in Earth's Insights is most problematic.

Callicott gives a much better account of Polynesian (of Hawaii) and North American Indian (Lakota and Ojibwa) environmental ethics (Chapter 6). More contextual information on kinship and social organization, on resources and ecosystems management systems is presented alongside the extrapolation from mythopoetic heritage.

In South America, the author focuses exclusively on the indigenous peoples of the Amazon (Tukano and Kayapo) (Chapter 7). The accounts of agro-ecology of the preHispanic Indians of the Andes region is quite well documented; yet the author is mute about these sources. The Inca land-use system (chakras) is still visible in today's Peru; the author ignores the whole subject. Even the Incan and other well-organized pre-Columbian resource-management systems and explicit and implicit environmental values are left out of the discussion. It is surprising to find no mention of the grand highland cultural traditions of the Incas and the Uros that still display bulky fragments of pre-Columbian practices and concepts regarding the environment.

Callicott's choice of putting African environmental thinking with that of Australian aborigines is beyond comprehension (Chapter 8). As examples of African environmental thinking and ethics, the authors picks up the agricultural Yoruba of Nigeria and the hunting-gathering !San Bushmen of the Kalahari desert of Southern Africa. This limited selection does not do justice to our understanding of African cultural reality. The great majority of the Africans are agro-pastoral people (agriculture and livestock breeding combined). The pure pastoralists constitute a significant portion of African population, mostly concentrated in East and North-East Africa. Desertification in sub-Saharan Africa is mostly related to overgrazing and massive and monotonous cash crop cultivation (problems created by the colonial powers first, and perpetuated by the international development community's prescriptions now). A close look into this reality (pastoralism) and a careful analysis of the traditional environmental ethics of these peoples in lieu of the negative developments in the environment and landscape could constitute a significant contribution. It is unfortunate that Callicott does not address this reality. 
The essay on postmodern environmental ethic (Chapter 9) is provocative. Any careful observer of the current environmental situation of the world is likely to agree with the author. But a few perplexities remain. The author affirms that the emerging global scientific worldview, happily, is not as conceptually dissonant with the world's many indigenous intellectual traditions as its predecessor, the mechanical worldview. I have doubts about this. First of all, the emerging global scientific worldview is based on the same (as in case of the late nineteenth and early twentieth century modern science) Western paradigm of the near-total knowability and programmability of the world. There is some anthropocentric arrogance (faith in the ultimate technological fix) in it, and there is a high potential of manipulative attitude. Let's not forget that the big progress in biotechnology, medicine, and pharmacy are very recent (say, postmodern) developments and I sincerely do not see any trace of the so-called good and kind "emerging global scientific worldview." Death and decay are continuously viewed as undesirable and, therefore, solutions of all sorts are pursued to avoid them, to prolong the life span. Frankly, this is far from the traditional indigenous ethics of many peoples. Even the deep concern with the environment among the so-called postmodernists seems more for the sake of better quality of life for the humans, not as a total outlook of improving the relationship amongst the creatures and the cosmos. The modern Western paranoia of death and decay is being transferred to other cultures through science, technology, and education. Science and technology are part of the problem and not the solution. The forward posture of fixing the things to improve the environmental situation may help in the short run (it is welcome) but it is not enough. What is needed is an inward posture of renouncing absolute human superiority and arbitrage. The author's affirmation that "conserving the human benefits and minimizing the environmental costs of modern technology will head the global agenda of the twenty-first century" (p.210) is too much in line with the forward posture.

Callicott has saved his best for last. Chapter 10 offers an elegant and interesting assessment of "stewardship" ethics in action. By reading the whole book an ordinary reader gets the impression that the author finds this ethical framework quite viable for the contemporary Western world, but he does not really regard it as really "fine" and "high." Callicott reports about the strong and successful (to some extent) Indian and Sri-Lankan environmental movements ("the Hindu environmental ethic in action" and "the Buddhist environmental ethics in action"). Throughout the book, one gets the impression that he considers the traditional environmental thinking of the Indian subcontinent to be quite good, better than the Western (Judeo-Christian-Moslem one) but not so "fine" and "high" as the Chinese, the Japanese, and some tribal ones. He also mentions the Buddhist forest conservation movement in Thailand. It is surprising that the author does not mention any instance of a traditional Chinese or Japanese environmental ethics (according to him, far superior to the Western and better than the Indian) in action. He also fails to say if they exist at all. If they do not exist then a serious question emerges: how the finest and the highest environmental thoughts (the Chinese and the Japanese, and some tribal ones, according to the author) do not generate any significant social and environmental action? If they exist, the reader becomes eager to know about them.

A qualified recommendation, then, would be for readers to include Earth's Insights among a list of works on comparative environmental ethics. The language and writing style tend to the baroque, overloaded by decorative elements. But Callicott is straightforward in delivering his oversimplified message, and is sure to prompt vigorous discussion. 